\title{
Statistical Alchemy for Drug Treatment of Generalized Anxiety Disorder: A Commentary on the Meta-Analysis by Baldwin et al. [BMJ 2011;342:d1199]
}

\author{
Giovanni A. Fava \\ Department of Psychology, University of Bologna, Bologna, Italy; Department of Psychiatry, State University of \\ New York at Buffalo, Buffalo, N.Y., USA
}

In the mid-1990s, Alvan R. Feinstein [1] compared meta-analyses to the alchemy that existed before modern scientific chemistry. The analogy was the hope to convert existing things into something better (changing base metals into gold) and the work with material that was heterogeneous and poorly identified. It was difficult to foresee in those days, however, the type of 'grand prix' model of meta-analysis applied by Baldwin et al. [2] to the drug treatment of generalized anxiety disorder, which was commented upon in an editorial by Furukawa [3], who had also authored a similar type of meta-analysis [4].

Baldwin et al. [2] conducted a systematic review of randomized controlled drug trials for generalized anxiety disorder. Trials were selected if they could allow determination of 'response' (the proportion of patients who experienced a reduction of at least $50 \%$ of their baseline score on the Hamilton anxiety scale) and 'remission' (the proportion of patients below a certain cutoff point on the scale). The authors failed to justify the choice of outcome measures, which have two major disadvantages: in generalized anxiety disorder we are dealing with a decrease in symptom intensity more than with a simple presence or absence [5], and categorization is hindered by the availability of different versions and translations of the Hamilton scale [6]. Indeed, unlike what is commonly found in individual trials, response and remission did not corre- late well in the meta-analysis [2], probably since this categorization is likely to be affected by the different characteristics of the trials, maximizing the inherent tendency of meta-analyses to violate the internal validity of the placebo comparison. Another very questionable procedure was to infer tolerability from withdrawals that may have been due to a number of reasons. This choice of outcome measures excluded a great number of studies concerned with older and low-cost medications, such as benzodiazepines, despite a large body of evidence pointing to their efficacy in generalized anxiety disorder [7]. Only two trials included a benzodiazepine (lorazepam), and no trial used a tricyclic. Berney et al. [8] performed a systematic review (up to 2006) of controlled trials on anxiety disorders that compared antidepressant drugs with benzodiazepines, and could identify only one trial with newer antidepressants. They concluded that the major change in prescribing patterns from benzodiazepines to newer antidepressants in anxiety disorders occurred without any comparative evidence [8]. A major driving force behind the change was the risk of dependence with benzodiazepines, even though withdrawal symptoms frequently occur with newer antidepressants upon tapering and discontinuation [9], even in optimal conditions, and do not necessarily subside within a few weeks [10]. A very recent report has raised preliminary but alarming data on

\section{KARGER}

Fax +4161306 1234 E-Mail karger@karger.ch www.karger.com

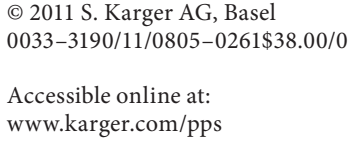

\footnotetext{
Giovanni A. Fava, MD

Department of Psychology, University of Bologna

Viale Berti Pichat 5

IT-40127 Bologna (Italy)

Tel. +39 051209 1339, E-Mail giovanniandrea.fava@ unibo.it
} 
the addictive potential of another drug included in the meta-analysis, pregabalin, compared with gabapentin and clonazepam [11]. By using categorical inclusion criteria, Baldwin et al. [2] obtained 26 studies that were published in 2001 or later and one that was published in 1999. It is unclear how many studies were eligible for inclusion but for the absence of the specific outcome measures chosen. All studies were sponsored by manufacturers, but the authors believed that these potential biases would have probably affected all drugs similarly [2]. This is like saying that if we have four speakers, each with a strong financial tie with industry, we could make a balanced symposium. By use of probabilistic mixed treatment metaanalysis, Baldwin et al. [2] ranked each treatment for effectiveness in terms of each outcome measure (response, remission, withdrawal).

Some clinical points required for a critical appraisal of data from meta-analyses and systematic reviews were missing from the discussion [12].

First of all, mention should be made of the fact that drug treatment is not mandatory in generalized anxiety disorder, and psychotherapies, in particular cognitive-behavior therapy, are at least as effective as pharmacological treatments [13]. This omission is particularly impressive in view of the recently increased availability of psychotherapeutic treatment within the UK National Health System $[14,15]$. Second, Baldwin et al. [2] acknowledged the fact that they could only evaluate the initial phase of treatment (6-8 weeks), whereas generalized anxiety disorder is a chronic condition that requires long-term treatment [16]. There is emerging awareness of serious and bothersome side effects that may ensue with long-term treatment with selective serotonin reuptake inhibitors (SSRI), such as high rates of sexual dysfunction, bleeding (in particular gastrointestinal), weight gain, risk of fracture and osteoporosis, and hyponatremia [17]. Is a modest decrease in anxiety worth these side effects in individual cases, particularly when evidence-based alternative interventions are available?

Further, generalized anxiety disorder frequently occurs in the setting of medical disease [18]. An issue that is frequently underestimated is the potential for drug interactions of antidepressant drugs, with special reference to the SSRI medications [19]. Both in terms of long-term treatment side effects and potential for drug interactions, benzodiazepines appear to be much safer than antidepressant drugs [20]. It may well be that the only potential advantage of SSRI versus benzodiazepines is represented by a lower impairment in cognitive and psychomotor skills [21].
Finally, there are two additional areas of concern regarding long-term treatment with antidepressant drugs in anxiety disorders. First, loss of clinical effect, with return of symptoms that is often refractory to drug increase, has been reported [9]. Second, there is also the risk that antidepressant drugs in anxiety disorders may actually predispose users to major depressive episodes [9] Fux et al. [22], for instance, observed the emergence of depressive symptoms in 7 of 80 patients $(9 \%)$ during treatment of panic disorder with fluvoxamine. These patients had no history of mood disorder, and no symptoms of depression were present before the fluvoxamine treatment. The symptoms abated when fluvoxamine was discontinued and tricyclic antidepressants or clonazepam were prescribed and reappeared when fluvoxamine was administered [22]. The data that are available in the literature [9] are not sufficient to postulate a depressogenic effect of antidepressants in generalized anxiety disorder, but should suggest a more cautious attitude, open to the possibility that the high co-occurrence of major depressive disorder and generalized anxiety disorder may be in part iatrogenic.

The disclosure requirements of the British Medical Journal allow the reader to reconstruct the genesis of the paper by Baldwin et al. [2], and may shed some light on methodological choices and critical omissions present, including the fact that the authors neither specifically searched for unpublished studies nor additional data. Lundbeck conceptualized and designed the study, and commissioned two of the authors (R.W. and R.L.) working in a private company to conduct the systematic review and meta-analysis, and prepare the manuscript. The two other authors (D.B. and D.T.) performed a critical review of the results and assisted in the development of the manuscript. Although the study was allegedly independent, all authors had financial ties with Lundbeck and other pharmaceutical companies which manufactured the drugs that were included and discussed in the meta-analysis. Toshi Furukawa [3], who was commissioned to write the editorial, also has financial ties with a number of pharmaceutical companies.

The meta-analysis performed by Baldwin et al. [2] is likely to yield misleading conclusions, particularly for the busy clinician who has no time to check its faulty procedures and the lack of appropriate clinical integration [2, 3]. The publication of this paper calls for a reassessment of journals' policies concerned with reviews, editorials and meta-analyses. These papers should be reserved to investigators free of substantial conflicts of interests, as discussed in detail elsewhere [23]. 


\section{References}

1 Feinstein AR: Meta-analysis: statistical alchemy for the 21st century. J Clin Epidemiol 1995;48:71-79.

2 Baldwin D, Woods R, Lawson R, Taylor D: Efficacy of drug treatments for generalised anxiety disorder: systematic review and meta-analysis. BMJ 2011;342:d1199.

$\checkmark 3$ Furukawa TA: Drug treatment for generalized anxiety disorder. BMJ 2011;342:d1216.

4 Cipriani A, Furukawa TA, Salanti G, Geddes JR, Higgins JP, Churchill R, Watanabe N, Nakagawa A, Omori IM, McGuire H, Tansella M, Barbui C: Comparative efficacy and acceptability of 12 new-generation antidepressants: a multiple-treatments meta-analysis. Lancet 2009;373:746-758.

5 Fava GA: The concept of recovery in affective disorders. Psychother Psychosom 1996; 65:2-13.

-6 Bech P: Fifty years with the Hamilton scales for anxiety and depression. Psychother Psychosom 2009;78:202-211.

7 Mitte K, Noack P, Steil R, Hautzinger M: A meta-analytic review of the efficacy of drug treatment in generalized anxiety disorder. J Clin Psychopharmacol 2005;25:141-150.

$\checkmark 8$ Berney P, Halperin D, Tango R, DaenikerDayer I, Schulz P: A major change of prescribing pattern in absence of adequate evidence: benzodiazepines versus newer antidepressants in anxiety disorders. Psychopharmacol Bull 2008;41:39-47.
9 Fava GA, Offidani E: The mechanisms of tolerance in antidepressant action. Progr Neuropsychopharmacol Biol Psychiatry DOI: $10.1016 /$ j.pnpbp.2010.07.026.

10 Fava GA, Bernardi M, Tomba E, Rafanelli C: Effects of gradual discontinuation of selective serotonin reuptake inhibitors in panic disorder with agoraphobia. Int J Neuropsychopharmacol 2007;10:835-838.

11 Schifano F, D’Offizi S, Piccione M, Corazza O, Deluca P, Davey Z, Di Melchiorre G, Di Furia L, Farré M, Flesland L, Mannonen M Majava A, Pagani S, Peltoniemi T, Siemann $\mathrm{H}$, Skutle A, Torrens M, Pezzolesi C, van der Kreeft P, Scherbaum N: Is there a recreational misuse potential for pregabalin? Psychother Psychosom 2011;80:118-122.

12 Sensky T: The effectiveness of cognitive therapy for schizophrenia: what can we learn from the meta-analyses? Psychother Psychosom 2005;74:131-134.

13 Mitte K: Meta-analysis of cognitive-behavioral treatments for generalized anxiety disorder: a comparison with pharmacotherapy. Psychol Bull 2005;131:785-795.

14 Layard R: The case for psychological treatment centres. BMJ 2006;332:1030-1032.

15 Marks I: Mental health clinics in the 21st century. Psychother Psychosom 2009;78: 133-138.
16 Rickels K, Etemad B, Khulid-Khan S, Lohoff FW, Rynn MA, Gallop RJ: Time to relapse after 6 and 12 months treatment of generalized anxiety disorder with venlafaxine extended release. Arch Gen Psychiatry 2010; 67:1274-1281.

17 Moret C, Isaac M, Briley M: Problems associated with long-term treatment with selective serotonin reuptake inhibitors. J Psychopharmacology 2009;23:967-974.

18 Fava GA, Porcelli P, Rafanelli C, Mangelli L, Grandi S: The spectrum of anxiety disorders in the medically ill. J Clin Psychiatry 2010; 71:910-914.

19 Nieuwstraten C, Labiris NR, Holbrook A: Systematic overview of drug interactions with antidepressant medications. Can J Psychiatry 2006;51:300-316

20 Dubovsky SL: Clinical Guide to Psychotropic Medications. New York, Norton, 2005.

$\checkmark 21$ Hindmarch I: Cognitive toxicity of pharmacotherapeutic agents in social anxiety disorder. Int J Clin Pract 2009;63:1085-1094.

22 Fux M, Taub M, Zohan J: Emergence of depressive symptoms during treatment for panic disorder with specific 5-hydroxytryptophan reuptake inhibitors. Acta Psychiatr Scand 1993;88:235-237.

23 Fava GA: Unmasking special interest groups: the key to addressing conflict of interest in medicine. Psychother Psychosom 2010;79: 203-207. 